\title{
Gamma-irradiated bacille calmette-guÉrin vaccination does not modulate the innate immune response during experimental human endotoxemia
}

\author{
LAC Hamers ${ }^{1,2^{*}}$, M Kox ${ }^{1}$, RJW Arts ${ }^{2}$, B Blok ${ }^{2}$, J Leentjens ${ }^{1,2}$, MG Netea ${ }^{2}$, P Pickkers ${ }^{1}$ \\ From ESICM LIVES 2015 \\ Berlin, Germany. 3-7 October 2015
}

\begin{abstract}
Introduction
Recent insights in sepsis pathology have led to the view that not the initial hyperinflammatory state, but rather a profoundly suppressed state of the immune system, also called immunoparalysis, accounts for the majority of sepsis-related deaths. Therefore, reconstitution of immunocompetence in sepsis is emerging as a promising therapeutic target to improve outcome. Bacille CalmetteGuérin (BCG) vaccine not only protects against tuberculosis, but exerts beneficial effects on other infectious diseases as well. These non-specific effects of BCG seem to be mediated by potentiation of adaptive immunity through heterologous effects, as well as epigenetic functional reprogramming of innate immune cells to an enhanced phenotype, a process described as 'trained immunity', which has been shown in vitro, ex vivo, and in animal models. Therefore, BCG-vaccination could represent a novel therapeutic option to treat sepsisinduced immunoparalysis, although its immunomodulatory effects in humans in vivo have not yet been investigated. Furthermore, the live BCG vaccine presents a potential risk of disseminated disease in immunoparalyzed patients, which can be circumvented by inactivating the vaccine through gamma-irradiation.
\end{abstract}

\section{Objectives}

To determine the effects of gamma-irradiated BCG-vaccination on the in vivo innate immune responses induced by human endotoxemia. Also, to determine the effects of gamma-irradiated BCG-vaccination on ex vivo responsiveness of leukocytes to various inflammatory stimuli.

${ }^{1}$ Radboud University Medical Center, Intensive Care Medicine, Nijmegen, the Netherlands

Full list of author information is available at the end of the article

\section{Methods}

In a randomized double blind placebo-controlled study, healthy male volunteers were vaccinated with gammairradiated BCG $(n=10)$ or placebo $(n=10)$ and received $1 \mathrm{ng} / \mathrm{kg}$ lipopolysaccharide (LPS) intravenously on day 5 after vaccination to assess the in vivo immune response. Peripheral blood mononuclear cells were stimulated with various related and unrelated pathogens 5 , 8 to 10 , and 25 to 35 days after vaccination to assess $e x$ vivo immune responses.

\section{Results}

LPS administration elicited a profound systemic immune response, characterized by increased levels of pro-and anti-inflammatory cytokines, hemodynamic changes, and flu-like symptoms. However, BCG neither modulated this in vivo immune response (Figure 1), nor ex vivo leukocyte responses at any time-point (Figure 2).

\section{Conclusions}

Gamma-irradiated BCG does not modulate the innate immune response in vivo in humans and is therefore unlikely to represent an effective treatment option to restore immunocompetence in patients with sepsisinduced immunoparalysis.

\section{Grant Acknowledgment}

M.G.N. was supported by a Vici grant of the Netherlands Organization for Scientific Research and an ERC Consolidator Grant (\#310372).

\section{Authors' details}

'Radboud University Medical Center, Intensive Care Medicine, Nijmegen, the Netherlands. ${ }^{2}$ Radboud University Medical Center, Internal Medicine, Nijmegen, the Netherlands. 


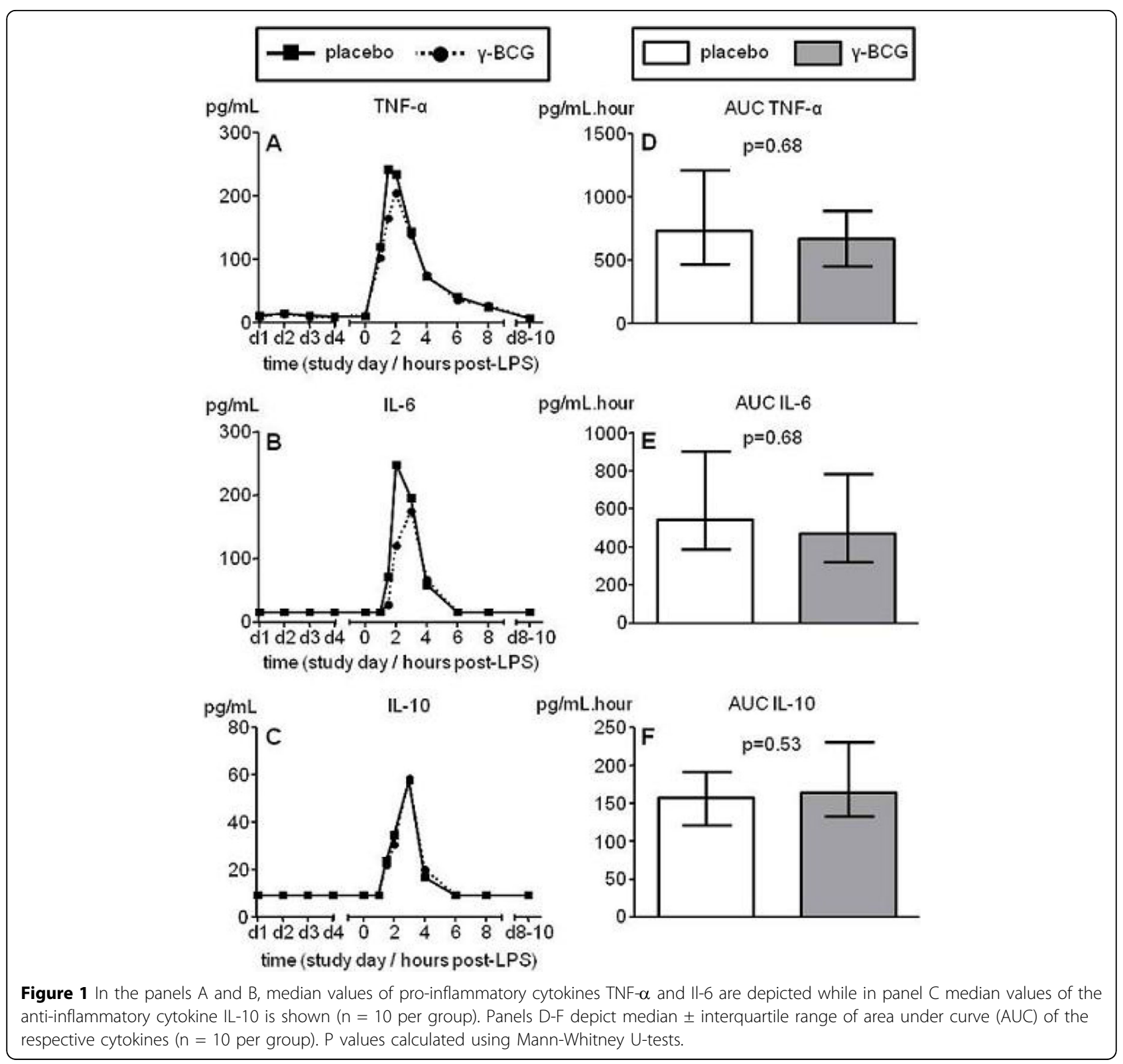

Published: 1 October 2015

doi:10.1186/2197-425X-3-S1-A419

Cite this article as: Hamers et al:: Gamma-irradiated bacille calmette-

guÉrin vaccination does not modulate the innate immune response

during experimental human endotoxemia. Intensive Care Medicine

Experimental 2015 3(Suppl 1):A419.

\section{Submit your manuscript to a SpringerOpen ${ }^{\circ}$ journal and benefit from:}

- Convenient online submission

- Rigorous peer review

- Immediate publication on acceptance

- Open access: articles freely available online

- High visibility within the field

- Retaining the copyright to your article

Submit your next manuscript at $>$ springeropen.com 


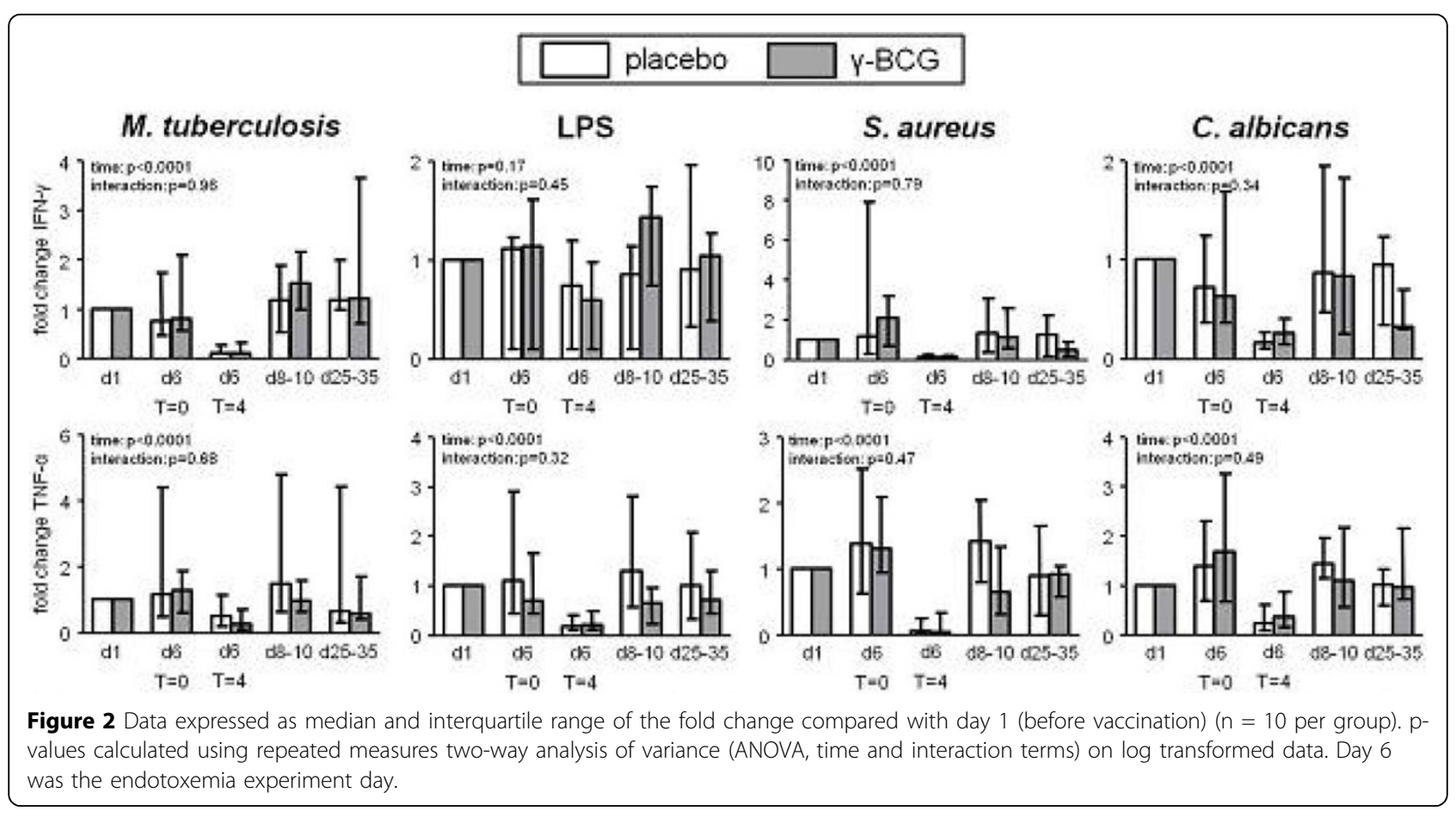

